\title{
Testing the Basic Target Zone Model on Swedish Data 1982-1990
}

\author{
Hans Lindberg \\ Sveriges Riksbank \\ 10337 Stockholm \\ Sweden \\ Paul Soderlind \\ Institute for International Economic Studies \\ Stockholm \\ and \\ Princeton University \\ Department of Economics \\ Princeton, NJ 08544 \\ USA
}

First draft: January, 1991

This version: May, 1992

Forthcoming in European Economic Reveiw

\begin{abstract}
The Swedish exchange rate band is studied using daily data on exchange rates and interest rate differentials for the 1980s. Applying a number of different statistical and econometrics techniques it is found that the first generation of target zone models cannot provide an adequate explanation of Swedish data. The main reasons are probably intra-marginal interventions by the Swedish central bank and time varying devaluation expectations.
\end{abstract}

\section{Contents}

1 Introduction 2

2 Testable implications of the Krugman model 3

3 Description of the data $\quad 6$

4 A study of the implications for distributions and correlations 8 
6 Estimating the basic TZ model June '85 to November '90

\section{Introduction}

The aim of this paper is to study some testable implications of the first generation of exchange rate target zone (TZ) models due to Krugman [13], using data for the Swedish krona during the 1980s. This will hopefully establish some facts about the Swedish exchange rate and perhaps give some impetus to further refinements of the TZ models. ${ }^{1}$

To meet these aims, we apply a number of straightforward, and when necessary, a few more sophisticated statistical/econometrics techniques. In most cases, the results seem to refute the basic TZ models. There are two probable explanations to this. First, the basic TZ model assumes central bank interventions only at the target zone boundaries. In practice, Sveriges Riksbank (the Swedish central bank) intervenes intra-marginally, which gives a different distribution of the exchange rate than predicted by the basic TZ model. Second, time varying devaluation expectations might cause a different correlation between the exchange rate and the interest rate differentials than predicted.

The rest of the paper is organized as follows. Section 2 summarizes the basic $\mathrm{TZ}$ model in order to extract the testable implications. Section 3 describes the data. Section 4 studies, among other things, the distributions and correlations of the exchange rate and interest rate differentials. Section 5 investigates whether the prediction power of an exchange rate equation is strengthened by taking into account non-linearities, which is an implication of the TZ model. Section 6 highlights the discrepancies between the model and data by first estimating the parameters in the TZ model and then performing a small Monte-Carlo experiment. Finally, section 7 summarizes our conclusions.

\footnotetext{
${ }^{1}$ The autohors thank Lars Horngren,Kjell Nordin, Peter Norman, the staff at the monentary and foreign exchange policy department at Sveriges Riksbank, a referee and participants in seminars at CEPR, IIES and Sveriges Riksbank for comments. We would also like to express our gratitude to Lars E.O Svensson for help and stimulating discussions. Hans Lindberg wishes to thank IIES for their hospitality. Paul Soderlind wishes to thank Jan Wallander Research Foundation and The Royal Swedish Academy of Sciences for financial support and Sveriges Riksbank for their hospitality and financial support. The views expressed in this paper are those of the authors and do not necessarily reflect those of Sveriges Riksbank.
} 


\section{Testable implications of the Krugman model}

The purpose of this section is to summarize the basic exchange rate target zone (TZ) model and its testable implications in order to prepare the ground for the statistical analysis. Much of the material is adopted from Krugman [13] and Svensson [23].

The starting point in this model is that exchange rates display many similarities with prices of assets traded on highly organized markets, for instance, shares. Similarly to this type of assets, foreign currencies can be traded with low transaction costs and storage is cheap. Evidently, this will give expectations about future exchange rates a key role in determining current rates. A standard way of formalizing this notion is

$$
s(t)=f(t)+\alpha d \mathrm{E}[s(t)] / d t,
$$

where $s(t)$ is the logarithm of the exchange rate at time $t$ (the price of the foreign currency in terms of the own currency), $f(t)$ a fundamental determinant of the currency, $\alpha$ a positive parameter and $\mathrm{E}$ the expectations operator. The expression $d \mathrm{E}[s(t)] / d t$ denotes $\lim _{\tau \rightarrow 0+}[\mathrm{E} s(t+\tau)-s(t)] / \tau$. Disregarding the discussion about the exact nature of $f(t)$, we follow Krugman [13] and let

$$
f(t)=m(t)+v(t)
$$

In (2) $m(t)$ can be thought of as the logarithm of the money stock, which is controlled by the central bank, and $v(t)$ as the logarithm of the velocity and a combination of other macro variables exogenous to the exchange rate, which for notational convenience will be referred to as just velocity. The velocity is assumed to be a Brownian motion

$$
d v(t)=\sigma d w(t) .
$$

(We disregard the case with a non-zero drift in $v(t)$ ). In (3) $\sigma$ is a constant instantaneous standard deviation and $w(t)$ a standard Wiener process, with $E(d w)=0$ and $E\left[(d w)^{2}\right]=d t$. The assumption of a Brownian motion is very convenient insofar as it provides a fairly simple closed form solution of the model.

Assume that the central bank wants to keep the exchange rate within a symmetric band $[-\bar{s}, \bar{s}]$ around zero. This can be achieved by defending a corresponding band for the fundamental $f(t)$. The band $[-\bar{f}, \bar{f}]$ is defended by the following policy rule:

$$
d m(t)=d L(t)-d U(t), \text { where }\left\{\begin{array}{l}
d L>0 \text { only if } f=-\bar{f} \\
d U>0 \text { only if } f=\bar{f}
\end{array},\right.
$$

and where $d L$ and $d U$ are infinitesimal interventions. Furthermore, it is assumed that this policy is credible, that is, the agents are sure about that no changes will take place in the policy rule. This rules out, among other things, devaluation expectations. 
The task here is to find a function $s[f(t)]$ describing the evolution of the exchange rate. Using (1) and applying Ito's lemma, we have that $s[f(t)]$ must fulfill the second order differential equation

$$
s[f(t)]=f(t)+\frac{1}{2} \alpha \frac{d^{2} s[f(t)]}{d f^{2}} \sigma^{2} .
$$

The general solution to (5) is

$$
s[f(t)]=f(t)-2 A \sinh [\lambda f(t)],
$$

sinh where $A$ remains to be determined. ${ }^{2}$ In an exchange rate regime with free float, $A=0$ and $s[f(t)]=f(t)$. In a target zone $A$ can be determined from the "smooth pasting" condition, which requires that $d s( \pm \bar{f}) / d f=0$. This gives the target zone exchange rate function

$$
s[f(t)]=f(t)-\sinh [\lambda f(t)] /[\lambda \cosh (\lambda \bar{f})], \text { where } \lambda=\left[2 /\left(\alpha \sigma^{2}\right)\right]^{\frac{1}{2}} .
$$

In order for the central bank to determine a suitable symmetric band around zero for the fundamental $[-\bar{f}, \bar{f}]$ which corresponds to the desired exchange rate band $[-\bar{s}, \bar{s}]$, the following equation must be solved for $\bar{f}$ :

$$
\bar{s}=\bar{f}-\tanh (\lambda \bar{f}) / \lambda .
$$

Diagram 1.1 illustrates the target zone exchange rate function and the free float exchange rate function for the parameter values $\alpha=3, \sigma=0.1$ and $[-\bar{s}, \bar{s}]=[-0.0225,0.0225]$. The exchange rate band is marked by the horizontal dotted lines. These parameter values will be used throughout this section and for the sake of familiarity they are similar to those used by Svensson [23] (only the band width differs). Note that the slope $d s[f(t)] / d f$ is always less than unity ("honeymoon effect") and that it approaches zero at the boundaries ("smooth pasting"). The function is non-linear ( $S$-shaped), with a more pronounced nonlinearity close to the boundaries.

Using a result in Harrison [11], we note that the unconditional probability density function for the fundamental is uniform,

$$
p^{f}(f)=1 /(2 \bar{f}) .
$$

Now, we have by the "change of variable in density function lemma" the unconditional density function for the exchange rate

$$
p^{s}(s)=\frac{1}{2 \bar{f}}\left|\frac{d s^{-1}(s)}{d s}\right|, \text { where } s \in(-\bar{s}, \bar{s}),
$$

where $s^{-1}(s)$ is the inverse of (7). Even though $s^{-1}(s)$ is only defined implicitly, the $p^{s}(s)$ function can easily be calculated numerically. The result is illustrated with the thick solid curve in Diagram 3.5a (disregard the other line

\footnotetext{
${ }^{2}$ sinh, cosh and tanh denotes the hyperbolic sine, cosine and tangent functions, respectively.
} 
and the bars for the moment). The density function is $U$-shaped, which is a combined effect of the assumption that the interventions only take place at the boundaries (which makes $\rho^{f}(f)$ uniform) and of the smooth pasting conditions $(d s( \pm \bar{f}) / d f=0)$. This implies that the exchange rate should have higher even moments (for instance, unconditional standard deviation) than a uniformly distributed variable.

Applying Ito's lemma on the exchange rate function $s[f(t)]$, we have the instantaneous (conditional) standard deviation of the exchange rate

$$
\sigma^{s}(s)=\left|\frac{d s(f)}{d f}\right| \sigma, \text { where } f=s^{-1}(s),
$$

which is $\cap$-shaped. This is illustrated with the solid curve in Diagram 3.8a.

Let $i(t)$ be the endogenous domestic and $i^{*}(t)$ the exogenous foreign instantaneous interest rates, and $\delta(t)=i(t)-i^{*}(t)$ the instantaneous interest rate differential. Assuming uncovered interest parity, we have $\delta(t)=d \mathrm{E} s[f(t)] / d t$, why the interest rate differential is a function of $f$ only. Using (1), this equals

$$
\delta[f(t)]=\frac{s[f(t)]-f(t)}{\alpha} .
$$

Since $d s / d f<1$ we have $d \delta / d f<0$ and the instantaneous interest rate differential is decreasing in the fundamental and hence in the exchange rate. However, it is probably more rewarding to study interest rates for finite terms. In order to do that we follow Svensson [25] and use an approximate form of uncovered interest parity (expressed as annualized interest rates)

$$
\delta[f(t), \tau]=\frac{\mathrm{E} s[f(t+\tau) \mid I(t)]-s[f(t)]}{\tau}, \tau>0
$$

where $\tau$ is the term measured in years (for instance, a 3 month bond has $\tau=1 / 4$ ) and $I(t)$ is the information set at period $t$. The first step in calculating $\delta[f(t), \tau]$ is to find a function for the expected exchange rate at $t+\tau$

$$
h[f(t), \tau]=\mathrm{E} s[f(t+\tau) \mid I(t)] .
$$

Svensson[1991c] shows that this function must fulfill

$$
\frac{d h[f(t), \tau]}{d \tau}=\frac{1}{2} \sigma^{2} \frac{d^{2} h[f(t), \tau]}{d f^{2}}, f \epsilon[-\bar{f}, \bar{f}], \tau>0
$$

with initial values and boundary conditions given by

$$
h[f(t), 0]=s[f(t)] \text { and } d h[-\bar{f}, \tau] / d f=d h[\bar{f}, \tau] / d f=0 .
$$

This is a parabolic partial differential equation, which can be solved numerically or with Fourier methods.otnoteIn an unpublished appendix to Svensson [25], Svensson describes an algorithm based on Gerald and Wheatley [10] and 
also obtains an analytical solution using Fourier methods. The appendix is included i n IIES Seminar Paper no. 466. Another good description of numerical solutions is found in Flannery et al [7]. It is worth noting that the non-linearity in $s[f(t)]$ carries over to $h[f(t), \tau]$, but to a smaller extent for large $\tau$. For a one-day forecasting horizon the function is essentially indistinguishable from the exchange rate function (illustrated in Diagram 1.1). Since $s[f(t)]$ is invertible, we could equally well write $h\left[s^{-1}(s), \tau\right]$, which points out the fact that a univariate forecasting equation for the exchange rate should show non-linearities, especially close to the band boundaries and for short forecasting horizons.

The solid curve in Diagram 3.3a illustrates the interest rate differential as function of the exchange rate for a three month bond. The curve has a somewhat non-linear shape with a negative relation between the interest rate differential and the exchange rate. It can also be shown that for longer terms the interest rate differential is less responsive to the exchange rate. In the same way as before, we can calculate the unconditional probability density functions for different terms. This is illustrated with the thick solid curve in Diagram 3.7a, again for a three month bond. For finite terms the probability density functions are $U$-shaped, much like the exchange rate, and it can be shown that for longer terms they are more compressed. ${ }^{3}$ Consequently, the longer terms should have lower even moments. Finally, the instantaneous (conditional) standard deviation of the interest rate differential is illustrated with the solid curve in Diagram 3.9a. For finite terms, the instantaneous standard deviation as function of the interest rate differential is $\cap$-shaped (as for the exchange rate).

To summarize, the more important testable implications of the basic TZ model are:

\begin{tabular}{|l|l|}
\hline Exchange rate & Interest rate differential (finite terms) \\
\hline (i) Non-linearity in univariate & (ii) Negative relation to exchange rate, \\
forecasting equation. & which is weaker for longer terms. \\
(iii) U-shaped distribution. & $\begin{array}{l}\text { (iv) U-shaped distribution, which is } \\
\text { denser for longer terms. } \\
\text { (vi) Inverse U-shape of conditional variance. }\end{array}$ \\
\hline
\end{tabular}

The rest of the paper is an attempt to evaluate these predictions using data for the Swedish krona during the 1980s.

\section{Description of the data}

The data in this study are daily and cover the period 82:01:01 — 90:11:15 (year:month:day). At the time, there was a unilateral target zone for the Swedish krona vis-a-vis a trade weighted currency basket. Later on, in May 1991, Sweden abandoned the currency basket and pegged the krona to the the-

\footnotetext{
${ }^{3}$ Svensson [25] discusses the qualitative difference between the finite term an the instanteneous interest rate differential.
} 
oretical ecu. However, the basic characteristics of the exchange rate system prevailed. The ecu peg is unilateral and the bandwidth is unchanged.

The exchange rate index (the exchange rate between the krona and the currency basket) was obtained from Sveriges Riksbank, and is for around 10.30 a.m. Central European time. The covered interest parity condition holds very well for Euro-deposit rates. Thus, forward exchange rate premia and interest rate differentials between Euro-deposits in different currencies contain essentially the same information. However, forward exchange rate premia that were quoted at the same time of the day were not available for all currencies in the currency basket. It was therefore preferable to use interest rate differentials in the study. Most of the the interest rate data were obtained from the database of the Bank for International Settlements (BIS). Interest rates are annualized simple bid rates at around 10 a.m. on Euro-currency deposits carrying a fixed maturity of 1,3,6 and 12 months, respectively. However, Euro-deposits denominated in Finnish markka were not available at the Bis and were instead obtained from Sveriges Riksbank. The interest rates on deposits denominated in the basket currency and Swedish kronor were compounded with the actual number of days from settlement to redemption with a 365 day year. However, we have not purged the data from effects of weekends and holidays at the redemption of the deposits.

The interest rates on deposits denominated in basket currency are constructed from the Euro-deposit rates according to the currencies' effective (rather than the official) weights in the Swedish currency basket. The reason for these weights is that the official weights in the Swedish arithmetic index formula do not represent the optimal weights in a basket portfolio (this problem does not occur in case of a geometric index formula). It is also worth noting that using the official weights is likely to lead to an underestimated interest rate differential. The calculation of the effective weights are described in an appendix to Lindberg and Söderlind [15].

However, we have been forced to make a small approximation due to the fact that Euro-deposit rates in Finnish markka were only available for the period 85:02:08 - 90:11:15 and hence not included in our basket deposit rate before that period. An additional approximation is that deposit rates on Spanish pesetas with a maturity of 12 -months were only included in the basket deposit rate for the period 85:04:30 - 90:11:15. Of course, for these periods with incomplete data, the weights of the remaining countries have been scaled accordingly to sum to unity. The partial exclusion of the Spanish pesetas is of only marginal importance since the effective weight of the pesetas is very low (around 1\%). The partial exclusion of the Finnish markka is possibly more problematic since the effective weight is fairly high (around 6\%). On the other hand, it can be argued that this lack of data for the markka simply reflects the lack of a developed Euro-deposit and forward exchange market for the markka in the early 1980s. In that case, exclusion of the markka contributes to a better representation of the actual investment possibilities that existed at that time.

The interest rate differentials between Euro-deposits in Swedish kronor and basket currency with the same maturity should be relatively free of political, 
credit, settlement and liquidity risk premia. However, it is possible or even plausible that the Swedish capital controls, which were progressively eased and finally abolished in July 1989, affected the interest rates on Euro-deposits denominated in Swedish kronor. An alternative would have been to use the domestic interest rates on Banker's certificate of deposits for the period January 1982 - June 1983, and Treasury bills for the period July 1983 - November 1990. However, the interest rate differentials between these domestic assets and the basket Euro-deposits are definitely affected by the kinds of risk premia mentioned above. In addition, the data on domestic interest rates are closing rates at $3.30 \mathrm{pm}$ and thus not completely comparable with the Euro-deposit rates available at the BIS.

Daily intervention data (spot interventions in the foreign exchange market) for the period 86:04:22-90:11:15 were obtained from Sveriges Riksbank. The Riksbank's daily intervention data are confidential and were therefore made available with some constraints in our use of them.

\section{A study of the implications for distributions and correlations}

In this section we study the testable implications on distributions and variances of the basic TZ model using daily data for Sweden. This is done by plotting and computing a number of statistics of the exchange rate and interest rate differentials for $1,3,6$ and 12 months time to maturity.

Diagram 3.1 shows the the Swedish currency index, which is a trade weighted average of the Swedish exchange rate against 15 other currencies, since its start 77:08:29. The index can be interpreted as an exchange rate corresponding to $s(t)$ in Section 2. Hence, a higher index indicates a weaker (cheaper) krona. The central parity was first set at 100. At the devaluation 81:09:14 it was changed to 111 and at the second devaluation 82:10:08 to 132. The exchange rate band was officially declared to be $\pm 1.5 \%$ in 85:06:27. For the earlier period, the Riksbank claims to have been defending an unofficial band of $\pm 2.25 \%$. The exchange rate band is marked by dotted lines in the diagram. In the subsequent analysis we will concentrate on the period 82:01:01 to 90:11:15 and distinguish between the periods before and after the narrowing of the band. We will call the two sub-periods regime I and II, respectively. At certain instances, we will also take a look at the period 86:02:01 - 89:10:31, used by Svensson [25] in a study of the relation between the exchange rate and the interest rate differential. This period is usually considered as a quite period with fairly modest interest rate differentials (read devaluation expectations). It should give the basic TZ model a very good chance. We will refer to this period as regime IIb.

Diagram 3.2 shows the currency index as a percentage deviation from central parity (which will henceforth be called just the exchange rate) and the annualized effective interest rate differential for the period 82:01:01-90:11:15. In order to save space, only the interest rate differential for 3 months to maturity 
is plotted in this and subsequent graphs. In general, the various interest rate differentials look very similar. As before, the exchange rate band is marked by dotted lines in the diagram. A few things are worth noting in the diagram. First, the interest rate differential has almost always been positive. Second, there are periods when the exchange rate and the interest rate differential seem to move in opposite directions as predicted by the basic TZ model, but the opposite is not uncommon either. Third, during the period summer 1985 until late 1989, the exchange rate was in the lower (stronger) half of the band almost all the time. Fourth, for at least the second half of the sample there is a tendency for the exchange rate to rise towards the end of the year.

Diagrams3.3a-b show scatter plots of the exchange rate and the interest rate differential (three months to maturity) for regime I and II. The theoretical prediction (ii) says that the interest rate differential should be a decreasing function of the exchange rate. This illustrated by the thick curve in Diagram 3.3a (throughout this we will mess up the diagrams for regime I with illustrations of the theoretical predictions). The lack of a simple pattern in data is disturbing for the basic TZ model. In fact, according to Tables 3.1-3.5 the correlation between the exchange rate and the interest rate differential is, in both regime I and II, positive and in contrast to the second part of prediction (ii) increasing with maturity. This clearly contradicts the theoretical predictions and will also rule out simple models of devaluation expectations, such as a constant expected devaluation. Moreover, the sheer level of the interest rate differential suggests that the the exchange rate band might have lacked credibility. These results for regime I and II should be contrasted to the negative correlations found by Svensson [25] for the period February 1986 to October 1989 (here called regime $\mathrm{IIb}$ ), and confirmed in Tables 3.2-3.5 for the same period (but using another data set). This period was characterized by fairly small and stable interest rate differentials, as shown in Diagram 3.2. In fact, most of the observations in the upper right quadrant of Diagram 3.3b are for the period after late 1989. One interpretation is that regime IIb was a period with fairly high credibility of the Swedish exchange rate band, which contributes to the support of the theoretical prediction. All this is confirmed in Diagram 3.4 which shows the expected exchange rate after one year as deviation from central parity, calculated in accordance with Svensson [24]. This is a crude measure of the credibility of the exchange rate band, with lack of credibility indicated by an expected exchange rate outside the exchange rate band. The expected exchange rate fluctuated heavily during the 1980s and the Swedish exchange rate band frequently lacked credibility. But, during regime IIb the expected exchange rate was fairly stable around the upper band boundary and showed no marked peaks.

Diagrams3.5a-b show the frequency distribution and a kernel estimate of the probability density function of the exchange rate for regime I and II. ${ }^{4}$ According to theory, as stated in prediction (iii) in section 2 and also illustrated by the thick curve in Diagram 3.5a, these should be $U$-shaped. In practice, they

\footnotetext{
${ }^{4}$ See Silverman [20] for a method for calculating this estimate. Here, the estimate is calculated at 200 different points, with a window size of $1.06 *$ standard deviation/sample length ${ }^{0.2}$ and the normal density function is used as the kernel.
} 
are all but $U$-shaped. This is consistent with the findings in Flood, Rose and Mathieson [8] for EMS data. Moreover, according to Table 3.1 the exchange rate shows no excess kurtosis (fatter tails than a normal distribution) at all, rather the opposite. In fact, the hypothesis that the exchange rate is normally distributed cannot be rejected for any of the regimes. In terms of the model in Section 1, this implies that the fundamental process $f(t)$ is more mean reverting than predicted by the model. This could, for instance, be explained by intramarginal interventions. That this is a fact is shown in Diagram 3.6, which plots the relative number of days with interventions on the spot exchange market across the exchange rate band. This is of course only one of many possible kinds of interventions. Nevertheless, it illustrates the main point: interventions take place all over the exchange rate band. ${ }^{5}$

Diagrams3.7 $a-b$ show the frequency distribution and a kernel estimate of the probability density function of the interest rate differential (3 months maturity) for the two regimes. The first part of prediction (iv) says that these distributions should be $U$-shaped, which is also illustrated by the thick curve in Diagram 3.7a. As before, this is not the case, even if Tables 3.2-3.5 show that most interest rate differentials have excess kurtosis. During regime II, while not in either regime I or regime IIb, all interest rate differentials are skewed to the left . This is tantamount to a clustering of observations at relatively low interest rate differentials combined with a long tail of observations at much higher differentials. It is worth noting that the the empirical distribution extends much further to the right than is consistent with a credible exchange rate band. This probably reflects short periods of high devaluation expectations, especially during the latter part of regime II, as discussed in conjunction with Diagram 3.4 .

The second part of prediction (iv) says that the unconditional standard deviation of the interest rate differential should decrease with the maturity seems to be consistent with data. According to Table 3.6 the interest rate differentials for 6 and 12 months have significantly lower standard deviation than the interest rate differential for 1 month.

Table 3.1 shows a considerable conditional heteroskedasticity of the exchange rate, but plots of the conditional standard deviations for regime I and II in Diagrams 3.8a-b reveal no clear pattern. But, the evidence of a $\cap$-shape, as predicted in $(v)$ and also illustrated in Diagram 3.8a, is weak. These observations carry over to the interest rate differentials (prediction $(v i)$ and illustrated in Diagram 3.9a) of different maturities in Tables 3.2-3.5, and is illustrated in Diagrams 3.9a-b for 3 months maturity.

Taken together, these facts imply that most of the predictions (ii)-(vi) in section 1 are more or less refuted. Hence, the basic exchange rate target zone model is far from being a good description of the Swedish exchange rate band. There are two issues here. First, the interest rate differentials suggest that the Swedish exchange rate band has not always been credible. Second, the

\footnotetext{
${ }^{5}$ See Lindberg and Soderlind [16] for a description and analysis of the intervention policy of Sveriges Riksbank.
} 
distribution of the exchange rate suggests that fundamentals are more mean reverting than predicted by the model. When we focus on regime IIb, which is chosen on purpose to be "friendly" to the basic TZ model, we see that the problem with low credibility is reduced substantially, but all the other problems regarding the distributions and variability remain.

\section{Testing for non-linearities June'85 to Novem- ber '90}

This section is an investigation of the existence of non-linearities in the Swedish exchange rate, as predicted in (i). We focus mostly on regime II (85:06:27 90:11:15), since the exact band limits (which are important for the non-linearity) were not known in regime I. For the sake of fairness to the basic TZ model, we will also look at some subsamples during regime II, among them regime IIb.

The basic exchange rate target zone equation, as illustrated in Diagram 1.1, is a non-linear ( $S$-shaped) function of the fundamental. This has the implication that the expected exchange rate, which is obtained by solving the partial differential equation (14), is a non-linear function of the current exchange rate. The degree of non-linearity is more pronounced for shorter forecasting horizons (time to maturity) and close to the boundaries of the exchange rate band. The international evidence of non-linearites is weak, as shown by the studies of Diebold and Nason [4] and Flood, Rose and Mathieson [8]. What about the Swedish krona?

One way of testing for non-linearities is to make use of a non-parametric method called locally weighted regression (LWR) and to compare its prediction errors with those of more conventional linear methods. If it turns out that the LWR produces lower prediction errors, then this ought to be a superior forecasting method and a partial proof of the existence of non-linearities.

The idea of the LWR is the following. Assume that we believe that the exchange rate is well predicted by $s_{t}=k\left(x_{t}\right)$, where $k$ is some unknown smooth function and $x_{t}$ a vector of variables, for instance, lags of $s_{t}$. Then, for each point $x^{*}$, which in practice is for each $x_{t}$ since it is highly unlikely that $x_{t}$ vectors are identical, estimate a parameter vector $\beta^{*}$ using weighted least squares. The weights of the observations $\left\{\ldots, x_{t-1}, x_{t+1}, \ldots\right\}$ in this regression is a tricube function of the euclidean distance of the respective observation and $x^{*}$. The predicted value of $s$ at $x^{*}$ is then formed as $x^{*} \beta^{*}$. This is repeated for each point $x^{*}$. This could be regarded as a series of linear approximations of the function $k$. A parameter $\xi,(0<\xi \leq 1)$ determines the smoothness of this approximation. Effectively, observations too far away gets a zero weight and the value of $\xi$ governs how far this "too far" is. With $\xi=1$ all but one observation in the sample would have a non-zero weight. We are agnostic about the best value of $\xi$ so several values will be tried. A detailed description of the LWR is found in Cleveland, Devlin and Grosse [3].

The non-linearity in the Swedish exchange rate is studied by comparing the 
standard errors of three different forecasting models

$$
\begin{gathered}
s_{t}=L W R\left(s_{\tau-1}, s_{\tau-2}, s_{\tau-3}, s_{\tau-4}, s_{\tau-5}\right)+u_{1 t}, \\
s_{t}=\omega_{0}+\omega_{1} s_{\tau-1}+u_{2 t}, \\
s_{t}=\gamma_{0}+\gamma_{1} s_{\tau-1}+\gamma_{2} s_{\tau-2}+\gamma_{3} s_{\tau-3}+\gamma_{4} s_{\tau-4}+\gamma_{5} s_{\tau-5}+u_{3 t} .
\end{gathered}
$$

In these equations, $\tau=t$ for in-sample comparison, but $\tau=t-j$ for a $j$ steps-ahead out-of-sample comparison. We make 1, 10 and 30 steps-ahead outof-sample forecasts. Of course, (16) and (17) are AR(1) and $\mathrm{AR}(5)$ processes, respectively. The LWR is computed using three different values of $\xi$, namely $0.3,0.5$ and 0.9 .

The forecasts are made for four different (sub-)periods: for the last 100 observations (summer and autumn 1990 when the exchange rate was in the middle of the band), for 1989 (when the exchange rate was close to the lower boundary much of the time), regime IIb and for the entire regime II. The major reason for looking at different subsamples is that any TZ model (including the Krugman model) exhibits most of the non-linearities close to the boundaries and is fairly linear in the middle of the band, as illustrated in Diagram 1.1. However, if, for some reason, the exchange rate is more mean reverting than predicted by the Krugman model (which we actually know from Diagram 3.5b) the non-linearities that may be present will only show up occasionally and will hence be hard to detect quantitatively. Therefore, there are two (not necessarily exclusive) possible explanations to a lack of non-linearity in data: the exchange rate function might be almost linear and/or the exchange rate distribution might have most of the probability mass in the middle of the band. By looking at periods when the exchange rate was close to a boundary (as in 1989), we are able isolate these effects.

The results, in the form of percentage standard errors of the predictions, are reported in Table 4.1a-d. It seems as if the (best) LWR is somewhat better than the linear methods in-sample, but on par or worse than the linear methods out-of-sample. Hence, the support for prediction (i) in Section 2 is at best very weak. One can conclude that the importance of non-linearities in univariate forecasting equations for the Swedish exchange rate is negligible.

\section{Estimating the basic TZ model June '85 to November '90}

This section provides an additional way of assessing the basic TZ model. It is an attempt to estimate the parameters in the basic TZ model for Swedish data for regime II (85:06:27-90:11:15) using a simulated moments estimator (SME). Equipped with estimates of the parameters, we race the model against data by means of a Monte Carlo experiment.

The idea behind the SME is to find those parameter values that minimizes a quadratic loss function in terms of weighted differences between empirical and 
simulated moments for the exchange rate. The choice of the SME method in the target zone context originates from Smith and Spencer [21] and stems from two facts. First, we have only vague ideas of what the fundamentals $(f)$ actually are and hence this variable is in practice non-observable. Second, the model is such that it is difficult (if not impossible) to arrive at analytical expressions for the moments of the exchange rate. We will here only give a broad picture of how we have implemented the SME approach. Details are found in Lindberg and Söderlind [16], while Ingram and Lee [12] provides a background.

The task is to estimate the parameters $[\alpha, \sigma, \bar{f}]$ in the model summarized by (2), (3), (4) and (7). But, we know that the exchange rate band $[-\bar{s}, \bar{s}]$ is $\pm 1.5 \%$ and that given $[\alpha, \sigma, \bar{s}]$, the boundary for fundamentals $\bar{f}$ is defined implicitly by (8). Hence, what needs to be estimated is just $\alpha$ and $\sigma$.

Let $\mu_{k}(y)$ denote the $k^{t h}$ central moment of some variable $y$. We use the following 8 central moments in the loss function: $\mu_{2}\left(s_{t}\right), \mu_{2}\left(\Delta s_{t}\right), \mu_{4}\left(s_{t}\right)$, $\mu_{1}\left(s_{t} s_{t-1}\right), \mu_{1}\left(\Delta s_{t} \Delta s_{t-1}\right), \mu_{1}\left(\Delta s_{t} \Delta s_{t-2}\right), \mu_{2}\left(\Delta s_{t} \Delta s_{t-1}\right)$ and $\mu_{2}\left(\Delta s_{t} \Delta s_{t-2}\right)$. The weight matrix is the covariance matrix of the corresponding empirical moments, which we estimate by the Newey-West [17] method with 10 lags.

The algorithm for the SME is in short:

(a) Generate a discrete approximation to the standard Wiener process $\left\{\Delta w_{t}\right\}=$ $\epsilon_{t} \sqrt{\Delta t}$, where $\epsilon_{t} \sim N(0,1)$ and $\Delta t=1 / 264$, which corresponds to daily observations. The sample length of simulations is 11230 and of empirical data 1240 . 6

(b) For each point $\left[\alpha_{i}, \sigma_{j}\right]$ in a grid, generate a series of fundamentals $\left\{f_{t}\right\}$ and calculate the exchange rate series $\left\{s_{t}\right\}$ by $(7)$ and the simulated moments. This is step is carried out for three different initial values $f_{0}=\{-\bar{f}, 0, \bar{f}\}$ and the three sets of simulated moments are subsequently averaged.

(c) The SME is given by the pair $\left[\alpha_{i}, \sigma_{j}\right]$ that minimizes the loss function.

All in all, some 150000 (although not evenly distributed) grid points have been investigated in the domain $\sigma \in[0.001,0.1]$ and $\alpha \in[0.015,120]$. It turns out that the loss function has a global minimum at $\sigma=0.0028$ and $\alpha=1.027$, but that the loss function is very flat along a curve (more or less a line) in the $\sigma \times \alpha$ space with a slope of $\Delta \alpha / \Delta \sigma \approx 16700$. Consequently, the standard errors are huge and neither parameter estimate is significantly different from zero at the $10 \%$ level.

There are several possible explanations for this problem. First, the choice of loss function could potentially be important. After some experimenting (changing moments, estimating the weight matrix with more off diagonal bands) it looks as if this is not the explanation. Second, we estimate the model with a drift term in the Brownian motion of $v(3)$ using the same loss function as above, with 29 grid points from $-1 \%$ to $1 \%$ per year of the drift term. Reassuringly, the loss function is minimized along the same curve in the $\sigma \times \alpha$ space as before with a zero drift. In fact, the estimation of the drift term is fairly tight. Third,

\footnotetext{
${ }^{6}$ The sample length here differs from that in Table 3.1 since we are only counting complete row vectors of all 8 moments. Since the data set includes some missing values and the moments use lags, the number of complete row vectors is less than the number of observations of the exchange rate.
} 
it could be the case that algorithm described above does not capture the essential features of the asymptotic distribution of the exchange rate in the model. There are at least two issues here: is the step size $\Delta t=1 / 264$ small enough to give a reasonable approximation of the Brownian motion and is the simulated sample size long enough? It turns out that the step size is not the problem, but that the sample size might be. The point is that $U$-shape of the model distribution makes it very important that simulated exchange rate traces out the entire support. But that can be a problem since the velocity $v$ might be very stable (low $\sigma$ ) or the boundaries far away (for instance, because of a high $\alpha$ ). As an example, the point estimate $(\sigma, \alpha)=(0.0028,1.027)$ implies that the expected time for moving from the middle of the band to one of the boundaries is around 38 years, while our simulations cover only 42 years. The obvious remedy to this is to extend the effective sample size. For computational reasons we simulate weekly exchange rate data (matching the same moments but for observations on wednesdays) and increase the sample size to 28075 . In this way the time span of the simulations is increased to almost 750 years. However, this gives the same kind of result as before, but with a tendency for the minimum loss function curve to be shifted to the left (lower $\sigma$ at a given $\alpha$ ), which of course means that the expected hitting time is higher.

The efforts to apply the SME to the basic TZ model give a dual problem: it seems as if the parameters $\alpha$ and $\sigma$ are hard to identify separately and that the point estimates may depend on the sample size. Along the minimum loss function curve the expected time to hitting the boundary is fairly constant, but the shape of the asymptotic distribution changes quiet a bit. This observation suggests that the two problems may very well be intertwined. The basic reason is that SME algorithm pushes the parameters in the direction where the simulated distribution tends to look less and less like it should ( $U$-shaped), and more and more like the actual exchange rate distribution, ( $\cap$-shaped: see Diagram 3.5b). Thus, there are very important, perhaps overwhelming, problems in applying the SME approach to the basic TZ model.

After this, what can be said about the parameter values along the minimum loss function curve(s)? Is it perhaps so that these parameter values all produce a good fit of data? In that case we would still have found some support for the model, in spite of our inability to nail down the very best parameter estimates. The answer is that they all produce really bad fit.

The large sample properties, which are used in the SME approach (holding in mind the potential problems of actually attaining a sufficiently large sample), show a very clear pattern over all estimation attempts. The moments of the exchange rate level are fairly well fitted, while the moments of the change in the exchange rate fare less well, by severely underestimating the volatility of the exchange rate. This contributes to the overwhelming rejection of the model as a whole: the fit of the model can easily be rejected at the $0.1 \%$ level.

We use a Monte Carlo experiment to study the small sample properties of the model. Here we choose the parameter values from point estimate $(\sigma, \alpha)=$ $(0.0028,1.027)$ from daily data. 1000 samples of the exchange rate are simulated. In each sample, the initial value of the exchange rate is set equal to the actual 
exchange rate value in 85:06:27 (0.51\%). Each sample consists of 1406 days (as in data) of which we set the same 52 days as in data to missing values, giving a total of 1354 observations. For each of these samples a number of statistics are computed. Kernel estimates of the distributions of these statistics are shown in Diagram 5.1, along with the corresponding value for data (marked with a vertical dotted line).

The first thing to note is that the simulated conditional standard deviation in Diagram 5.1d is much (in fact always) lower than the empirical counterpart and on average more than 4 times lower. This has the effect that the simulated exchange rate stays close to its initial value. In Diagram $5.1 \mathrm{~d}$ we see that the range (maximum minus minimum) is also much smaller than for data. Since the initial value is $0.51 \%$ this means that the distribution for the maximum in Diagram 5.1c is well located, while the distributions for the minimum in Diagram 5.1b and the mean in Diagram 5.1a are way off. Of course, the low variability of the exchange rate means that it hits the boundary very seldom. Since, the boundaries are the only factor that creates mean reversion in the model, it is not surprising that the simulated series look as if they contained a unit root as shown in Diagram 5.1i. On the other hand, the simulated statistics for skewness, kurtosis and normality are well located and illustrate how short simulations tend to look similar to a normally distributed variable. These results are, as could be guessed, very similar for all parameter paris along the minimum loss function curve through $(\sigma, \alpha)=(0.0028,1.027)$. With an even lower level of $\sigma$, as suggested by the estimation on weekly data, the results become even more extreme.

Our conjecture is that the basic TZ model cannot be successfully estimated on Swedish data using any approach, since the model is simply misspecified. The parameter values that we do get by using the SME approach implies an implausible economic behaviour compared with data.

\section{Conclusions}

This paper shows that the first generation of target zone models is far from being a good description of the Swedish exchange rate band. Our results seem to refute the models in most cases. In this summary we would like to point out what we believe are the crucial aspects that must be incorporated in a target zone model. Some research in this area seem to be well suited for capturing these aspects and we try to relate to these papers.

First, according to Swedish data there is a positive correlation between the exchange rate and the interest rate differential for most sub-periods. This clearly contradicts the theoretical prediction of a deterministic negative relation between the exchange rate and interest rate differential. Diagram 3.4 suggested that time-varying devaluation expectations must be accounted for. Bertola and Svensson [2] has developed a theoretical target zone model with stochastic time varying devaluation expectations. On the basis of that extension, Rose and Svensson [19] estimate time varying devaluation expectations for the French 
Franc/German Mark exchange rate and Lindberg, Svensson and Söderlind [14] for the Swedish krona.

Second, the frequency distribution of the exchange rate is not $U$-shaped as predicted by the basic target zone models, rather the opposite. This could be explained by the fact that Sveriges Riksbank frequently makes intra-marginal interventions, which was illustrated in Diagram 3.6. The presence of intramarginal interventions and the hump shaped distribution of the exchange rate suggest that a mean reverting policy rule would fit Swedish data better. Delgado and Dumas [5] use a regulated Ornstein-Uhlenbeck process instead of the regulated Brownian motion, which tend to give a hump shaped distribution. Lindberg and Söderlind [16] combines this model with the devaluation model of Bertola and Svensson [2] and attempt to estimate the exchange rate function for Swedish data. This seems to improve substantially on the basic TZ model.

\section{A The Currency Basket Index}

The Swedish currency basket index s, which has been in use since August 1977 is calculated according to

$$
\tilde{s}_{t}=A_{t} \sum_{i} \frac{w_{t}^{i} \tilde{s}_{\text {basse }}^{i}}{\tilde{s}_{t}^{i}} \frac{\tilde{s}_{t}^{S E K}}{\tilde{s}_{\text {base }}^{S E K}},
$$

where $\tilde{s}_{t}^{i}$ is the exchange rate, at time $t$, for currency $i=\{a t s, b e c, c a d, c g f$, dem, dkk, frf, gbp, itl, jpy, nlg, nok, usd, fim, esp $\}$ in US dollars. $\tilde{s}_{b a s e}^{i}$ is the corresponding exchange rate in August 1977 (base period for the index). The official weights $w_{t}^{i}$ and the adjustment factor $A_{t}$ are found in the table A1 below. The official weights are based on five-year moving averages of shares in Swedish imports plus exports and are changed the $1^{\text {st }}$ of April each year. The adjustment factor $A_{t}$ is also changed at the $1^{\text {st }}$ of April in order to keep the new index level at that date equal to the index level that would have prevailed if the old official weights had still applied. 


\begin{tabular}{|rrrrrrrrr|}
\hline \multicolumn{7}{|c|}{ Table A1: Basket weights and adjustment factor } \\
\hline \hline$t$ & $w^{\text {ats }}$ & $w^{\text {bec }}$ & $w^{\text {cad }}$ & $w^{\text {chf }}$ & $w^{\text {dem }}$ & $w^{\text {dkk }}$ & $w^{\text {frf }}$ & $w^{g b p}$ \\
\hline 1977 & 1.9 & 3.9 & 1.2 & 2.6 & 16.7 & 9.5 & 5.3 & 13.9 \\
1978 & 1.9 & 3.8 & 1.2 & 2.5 & 16.9 & 9.5 & 5.3 & 13.4 \\
1979 & 1.9 & 3.7 & 1.2 & 2.5 & 17.0 & 9.5 & 5.4 & 13.1 \\
1980 & 1.8 & 3.7 & 1.2 & 2.4 & 17.1 & 9.5 & 5.5 & 13.1 \\
1981 & 1.8 & 3.7 & 1.2 & 2.4 & 17.1 & 9.3 & 5.6 & 13.1 \\
1982 & 1.7 & 3.7 & 1.1 & 2.4 & 16.9 & 8.9 & 5.6 & 13.1 \\
1983 & 1.6 & 3.7 & 1.1 & 2.3 & 16.6 & 8.5 & 5.6 & 13.0 \\
1984 & 1.5 & 3.8 & 1.1 & 2.2 & 16.2 & 8.2 & 5.5 & 13.2 \\
1985 & 1.4 & 3.7 & 1.0 & 2.1 & 15.9 & 8.0 & 5.4 & 12.9 \\
1986 & 1.3 & 3.6 & 1.1 & 2.0 & 15.5 & 7.9 & 5.2 & 12.8 \\
1987 & 1.3 & 3.6 & 1.1 & 2.0 & 15.6 & 7.8 & 5.2 & 12.2 \\
1988 & 1.3 & 3.6 & 1.1 & 2.1 & 16.0 & 7.8 & 5.2 & 11.7 \\
1989 & 1.3 & 3.7 & 1.2 & 2.1 & 16.4 & 7.6 & 5.2 & 11.1 \\
1990 & 1.4 & 3.7 & 1.2 & 2.2 & 16.7 & 7.4 & 5.4 & 10.7 \\
\hline
\end{tabular}

Table A1: Basket weights and adjustment factor cont.

\begin{tabular}{|rrrrrrrrr|}
\hline \hline$t$ & $w^{\text {itl }}$ & $w^{j p y}$ & $w^{\text {nlg }}$ & $w^{\text {nok }}$ & $w^{\text {usd }}$ & $w^{\text {fim }}$ & $w^{e s p}$ & $A$ \\
\hline 1977 & 3.2 & 2.1 & 5.1 & 9.9 & 16.0 & 7.2 & 1.5 & 1.000000 \\
1978 & 3.3 & 2.4 & 5.1 & 10.2 & 16.0 & 7.1 & 1.4 & 1.000000 \\
1979 & 3.4 & 2.6 & 5.2 & 10.1 & 16.0 & 7.1 & 1.3 & 1.000000 \\
1980 & 3.4 & 2.6 & 5.2 & 9.8 & 16.3 & 7.2 & 1.2 & 1.000000 \\
1981 & 3.6 & 2.6 & 5.2 & 9.4 & 16.5 & 7.3 & 1.2 & 1.000000 \\
1982 & 3.6 & 2.7 & 5.1 & 9.2 & 17.4 & 7.4 & 1.2 & 1.000000 \\
1983 & 3.7 & 2.7 & 5.2 & 9.3 & 18.1 & 7.4 & 1.2 & 0.999318 \\
1984 & 3.6 & 2.7 & 5.1 & 9.4 & 19.1 & 7.2 & 1.2 & 0.996692 \\
1985 & 3.6 & 2.9 & 4.9 & 9.4 & 20.7 & 6.9 & 1.2 & 0.988950 \\
1986 & 3.5 & 3.0 & 4.8 & 9.3 & 22.2 & 6.6 & 1.2 & 0.985859 \\
1987 & 3.6 & 3.1 & 4.7 & 9.2 & 22.8 & 6.5 & 1.3 & 0.984710 \\
1988 & 3.7 & 3.3 & 4.6 & 9.0 & 22.8 & 6.5 & 1.3 & 0.981203 \\
1989 & 3.8 & 3.6 & 4.6 & 8.7 & 22.5 & 6.7 & 1.5 & 0.977405 \\
1990 & 4.0 & 3.8 & 4.6 & 8.5 & 21.9 & 6.9 & 1.6 & 0.974516 \\
\hline
\end{tabular}

Let $s^{i}$ denote the Swedish exchange rate in terms of currency $i$. Then, the currency basket index can also be written as

$$
s_{t}=A_{t} \sum_{i} \frac{w_{t}^{i} s_{t}^{i}}{s_{\text {base }}^{i}} .
$$

Since $\left(s_{t}^{i} / s_{\text {base }}^{i}-1\right) * 100$ is the percentage change in the Swedish exchange rate in terms of currency $i$ since August 1977, we note that the index $s_{t}$ is a weighted average of percentage changes of the Swedish exchange rate in terms of the basket currencies. Yet another way of looking at the definition is to regard $A_{t} w_{t}^{i} / s_{\text {base }}^{i}$ as a kind of weight. Then $s_{t}$ is just an ordinary weighted average of the current Swedish exchange rates. Actually, this is the most useful inter- 
pretation. If an investor buys a portfolio consisting of the number $A_{t} w_{t}^{i} / s_{\text {base }}^{i}$ of currency $i$, for instance, $1 * 3.3 / 882.311$ Italian Lire in 1978 where 882.311 was the sek/itl exchange rate in august 1977, then this portfolio will cost him exactly $s_{t}$ sek and at time $t+1$ is will be worth exactly $s_{t+1} s e k$. In terms of value shares of the portfolio, the value shares that achieves this are

$$
\hat{w}_{t}^{i}=\frac{\frac{w_{t}^{i} s_{t}^{i}}{s_{\text {base }}^{i}}}{\sum_{i} \frac{w_{t}^{i} s_{t}^{i}}{s_{\text {base }}^{i}}}
$$

Hence, the effective weights $\hat{w}_{t}^{i}$ are functions of the current exchange rates. For our purposes it is important to note that if the strong currencies (those whose value has increased more than the basket) have had lower interest rates during the historical period that we investigate, then using the basket weights will give an underestimated interest rate differential.

\section{B Tables}

\begin{tabular}{|lrrrr|}
\hline \multicolumn{5}{c}{ Table 3.1: Exchange rate } \\
\\
\hline \hline Mean & 20101-901115 & $820101-850626$ & $860201-891031$ & $850627-901115$ \\
Uncond std dev & -0.515 & -0.367 & -0.757 & -0.611 \\
Cond std dev & 0.645 & 0.785 & 0.430 & 0.514 \\
Min & 0.118 & 0.159 & 0.078 & 0.082 \\
Max & -2.106 & -2.106 & -1.515 & -1.515 \\
No skewness & 1.409 & 1.409 & 0.242 & 0.818 \\
No excess kurt & 0.322 & -0.031 & 0.341 & 0.367 \\
Normality & -0.220 & -0.566 & -0.851 & -0.808 \\
Homosked & 43.038 & 11.788 & 46.709 & 67.264 \\
Unit root & $115.326^{*}$ & $48.966^{*}$ & $57.285^{*}$ & $87.177^{*}$ \\
Observations & $-4.003^{*}$ & -2.678 & -2.776 & $-3.013^{*}$ \\
\hline
\end{tabular}

- The conditional standard deviation is for one step-ahead forecasts error based on a fifth order AR.

- Rejection on the 5\% significance level, for skewness, kurtosis, normality, homoskedasticity and unit root tests, is denoted by *

- The asymptotic distribution for the skewness measure is $N(0,6 / T)$, given that the observations are independent, which is not the case here. The $5 \%$ critical value has been calculated by a Monte Carlo experiment: simulate a fitted $\operatorname{AR}(5)$ process 250 times and calculate the statics gives an estimate of the variance. 
- Bera-Jarque's test for normality. The asymptotic distribution for the statistics is $\chi^{2}(2)$, given that the observations are independent. Due to autoregression, the $5 \%$ critical value has been calculated by means of a Monte Carlo experiment.

- White's test of conditional homoskedasticity. The test statistics is asymptotically distributed as $\chi^{2}(m)$, where $m$ is the number of quadratic terms in the auxiliary regression (here 20). The variables used in the auxiliary regression are 5 lags of the series studied.

- Perron's $Z\left(t_{\mu}\right)$ test (using 25 lags). The statistics should be lower than -2.86 in order to reject the hypothesis of unit root (non-stationarity) on the $5 \%$ significance level.

\begin{tabular}{|lrrrr|}
\hline \multicolumn{5}{c}{ Table 3.2: Interest rate differential (1 month) } \\
& $820101-901115$ & $820101-850626$ & $860201-891031$ & $850627-901115$ \\
\hline \hline Mean & 2.757 & 2.415 & 2.407 & 2.975 \\
Uncond std dev & 1.845 & 2.175 & 0.786 & 1.561 \\
Cond std dev & 0.361 & 0.520 & 0.158 & 0.222 \\
Min & -6.231 & -6.231 & 0.484 & 0.484 \\
Max & 11.280 & 11.280 & 4.953 & 8.105 \\
No skewness & $0.503^{*}$ & 0.099 & 0.467 & $1.587^{*}$ \\
No excess kurt & $2.798^{*}$ & $2.051^{*}$ & 0.189 & $2.177^{*}$ \\
Normality & $806.158^{*}$ & $150.784^{*}$ & 35.196 & $824.653^{*}$ \\
Homosked & $266.900^{*}$ & $123.282^{*}$ & $152.961^{*}$ & $46.676^{*}$ \\
Unit root & $-4.723^{*}$ & $-3.315^{*}$ & -3.898 & $-3.405^{*}$ \\
Corr(exch rate) & 0.092 & 0.068 & -0.406 & 0.197 \\
Observations & 2188 & 852 & 929 & 1336 \\
\hline
\end{tabular}

\begin{tabular}{|lrrrr|}
\hline \multicolumn{5}{c}{ Table 3.3: Interest rate differential (3 months) } \\
& $820101-901115$ & $820101-850626$ & $860201-891031$ & $850627-901115$ \\
\hline \hline Mean & 2.676 & 2.322 & 2.342 & 2.902 \\
Uncond std dev & 1.589 & 1.840 & 0.628 & 1.360 \\
Cond std dev & 0.222 & 0.288 & 0.124 & 0.173 \\
Min & -1.808 & -1.808 & 0.692 & 0.692 \\
Max & 8.381 & 8.381 & 4.503 & 8.189 \\
No skewness & $0.829^{*}$ & 0.583 & 0.252 & $1.666^{*}$ \\
No excess kurt & $2.193^{*}$ & $1.416^{*}$ & 0.408 & $2.650^{*}$ \\
Normality & $688.980^{*}$ & 119.500 & 16.277 & $1009.118^{*}$ \\
Homosked & $210.047^{*}$ & $114.207^{*}$ & $176.392^{*}$ & $133.763^{*}$ \\
Unit root & $-3.297^{*}$ & -1.379 & $-3.481^{*}$ & $-3.392^{*}$ \\
Corr(exch rate) & 0.124 & 0.093 & -0.419 & 0.254 \\
Observations & 2188 & 852 & 929 & 1336 \\
\hline
\end{tabular}




\begin{tabular}{|lrrrr|}
\hline \multicolumn{5}{c}{ Table 3.4: Interest rate differential (6 months) } \\
& $820101-901115$ & $820101-850626$ & $860201-891031$ & $850627-901115$ \\
\hline \hline Mean & 2.427 & 1.899 & 2.232 & 2.763 \\
Uncond std dev & 1.422 & 1.635 & 0.527 & 1.148 \\
Cond std dev & 0.197 & 0.246 & 0.113 & 0.159 \\
Min & -1.841 & -1.841 & 0.627 & 0.627 \\
Max & 7.697 & 7.388 & 3.896 & 7.697 \\
No skewness & 0.579 & 0.702 & -0.137 & $1.449^{*}$ \\
No excess kurt & $1.873^{*}$ & $1.652^{*}$ & 0.809 & $2.085^{*}$ \\
Normality & $442.012^{*}$ & 166.896 & 28.201 & $709.114^{*}$ \\
Homosked & $191.503^{*}$ & $92.543^{*}$ & $250.315^{*}$ & $74.300^{*}$ \\
Unit root & $-3.140^{*}$ & -1.085 & $-3.508^{*}$ & $-3.379^{*}$ \\
Corr(exch rate) & 0.124 & 0.102 & -0.378 & 0.315 \\
Observations & 2188 & 852 & 929 & 1336 \\
\hline
\end{tabular}

\begin{tabular}{|lrrrr|}
\hline \multicolumn{5}{c}{ Table 3.5: Interest rate differential (12 months) } \\
& $820101-901115$ & $820101-850626$ & $860201-891031$ & $850627-901115$ \\
\hline \hline Mean & 2.124 & 1.390 & 2.117 & 2.597 \\
Uncond std dev & 1.273 & 1.348 & 0.519 & 0.962 \\
Cond std dev & 0.193 & 0.255 & 0.111 & 0.142 \\
Min & -1.689 & -1.689 & 0.512 & 0.512 \\
Max & 6.321 & 6.321 & 3.284 & 6.111 \\
No skewness & 0.207 & $0.901^{*}$ & -0.546 & $0.779^{*}$ \\
No excess kurt & 0.634 & $1.927^{*}$ & 0.480 & 0.316 \\
Normality & 52.470 & $249.210^{*}$ & 55.013 & 140.644 \\
Homosked & $155.406^{*}$ & $48.701^{*}$ & $281.803^{*}$ & $103.952^{*}$ \\
Unit root & $-3.007^{*}$ & -1.536 & $-3.339^{*}$ & -2.556 \\
Corr(exch rate) & 0.130 & 0.154 & -0.271 & 0.374 \\
Observations & 2193 & 859 & 929 & 1334 \\
\hline
\end{tabular}

\begin{tabular}{|lrrrr|}
\hline \multicolumn{5}{|c|}{$\begin{array}{c}\text { Table 3.6: Test of different unconditional variance } \\
\text { from 1 month interest rate differential }\end{array}$} \\
& $820101-901115$ & $820101-850626$ & $860201-891031$ & $850627-901115$ \\
\hline \hline Int diff $(3 \mathrm{~m})$ & $-0.742^{*}$ & -1.343 & $-0.158^{*}$ & -0.588 \\
Int diff $(6 \mathrm{~m})$ & $-1.381^{*}$ & $-2.056^{*}$ & $-0.259^{*}$ & $-1.119^{*}$ \\
Int diff $(12 \mathrm{~m})$ & $-1.782^{*}$ & $-2.914^{*}$ & $-0.267^{*}$ & $-1.512^{*}$ \\
\hline
\end{tabular}

The test is performed using the Newey-West [17] covariance matrix, which takes into account serial correlation and heteroskedasticity. 


\begin{tabular}{|c|c|c|c|c|}
\hline \multicolumn{5}{|c|}{$\begin{array}{c}\text { Table 4.1a: In-the-sample prediction errors: standard deviation, \% } \\
\text { from } 1 \text { months interest rate differential }\end{array}$} \\
\hline & Last 100 observations & 1989 & $860201-891031$ & $850627-901115$ \\
\hline$\overline{\operatorname{Lwr}(5) \xi=0.30}$ & $\overline{\overline{5.34}}$ & 7.51 & $\overline{7.39}$ & $\overline{7.98}$ \\
\hline $\operatorname{Lwr}(5) \xi=0.50$ & 6.61 & 7.67 & 7.61 & 8.12 \\
\hline $\operatorname{Lwr}(5) \xi=0.90$ & 7.43 & 7.77 & 7.73 & 8.19 \\
\hline $\operatorname{AR}(1)$ & 7.97 & 7.91 & 7.86 & 8.29 \\
\hline $\operatorname{AR}(5)$ & 7.78 & 7.80 & 7.77 & 8.21 \\
\hline
\end{tabular}

\begin{tabular}{|lrrrr|}
\hline Table 4.1b: One-step-ahead out-of-sample predictions: & \multicolumn{3}{c|}{ standard deviation, \% } \\
& from 1 months interest & rate differential & \\
& Last 100 observations & 1989 & $860201-891031$ & $850627-901115$ \\
\hline \hline $\operatorname{Lwr}(5) \xi=0.30$ & 8.10 & 8.51 & 8.53 & 9.60 \\
$\operatorname{Lwr}(5) \quad \xi=0.50$ & 7.93 & 8.49 & 8.36 & 9.42 \\
$\operatorname{Lwr}(5) \xi=0.90$ & 7.89 & 8.49 & 8.26 & 9.33 \\
$\operatorname{AR}(1)$ & 7.95 & 8.50 & 8.17 & 9.25 \\
$\operatorname{AR}(5)$ & 7.84 & 8.52 & 8.23 & 9.31 \\
\hline
\end{tabular}

\begin{tabular}{|lrrrr|}
\hline Table 4.1c: 10-steps-ahead out-of-sample predictions: & \multicolumn{3}{c|}{ standard deviation, \% } \\
& from 1 months interest rate differential & \\
& Last 100 observations & 1989 & $860201-891031$ & $850627-901115$ \\
\hline \hline $\operatorname{Lwr}(5) \xi=0.30$ & 20.13 & 27.79 & 25.86 & 26.16 \\
$\operatorname{Lwr}(5) \quad \xi=0.50$ & 18.70 & 27.40 & 24.36 & 25.13 \\
$\operatorname{Lwr}(5) \xi=0.90$ & 19.01 & 26.89 & 23.15 & 24.82 \\
$\operatorname{AR}(1)$ & 18.28 & 26.76 & 22.49 & 24.78 \\
$\operatorname{AR}(5)$ & 18.96 & 26.47 & 22.73 & 24.72 \\
\hline
\end{tabular}

\begin{tabular}{|lrrrr|}
\hline Table 4.1d: 30-steps-ahead out-of-sample predictions: standard deviation, \% \\
& $\begin{array}{c}\text { from 1 months interest rate differential } \\
\text { from } 100 \text { observations }\end{array}$ & 1989 & $860201-891031$ & $850627-901115$ \\
\hline \hline $\operatorname{Lwr}(5) \xi=0.30$ & 45.57 & 22.07 & 56.27 & 44.01 \\
$\operatorname{Lwr}(5) \quad \xi=0.50$ & 44.73 & 22.55 & 51.25 & 43.44 \\
$\operatorname{Lwr}(5) \quad \xi=0.90$ & 44.23 & 21.97 & 44.23 & 43.10 \\
$\operatorname{AR}(1)$ & 43.86 & 20.44 & 41.23 & 43.50 \\
$\operatorname{AR}(5)$ & 43.54 & 21.76 & 41.74 & 42.71 \\
\hline
\end{tabular}

\section{References}

[1] Bertola, G., and R.J. Caballero (1990), "Target Zones and Realignments", CEPR Discussion Paper No. 398

[2] Bertola, G., and L.E.O. Svensson (1990) "Stochastic Devaluation Risk and the Empirical Fit of Target Zone Models“, IIES Seminar Paper no. 481 


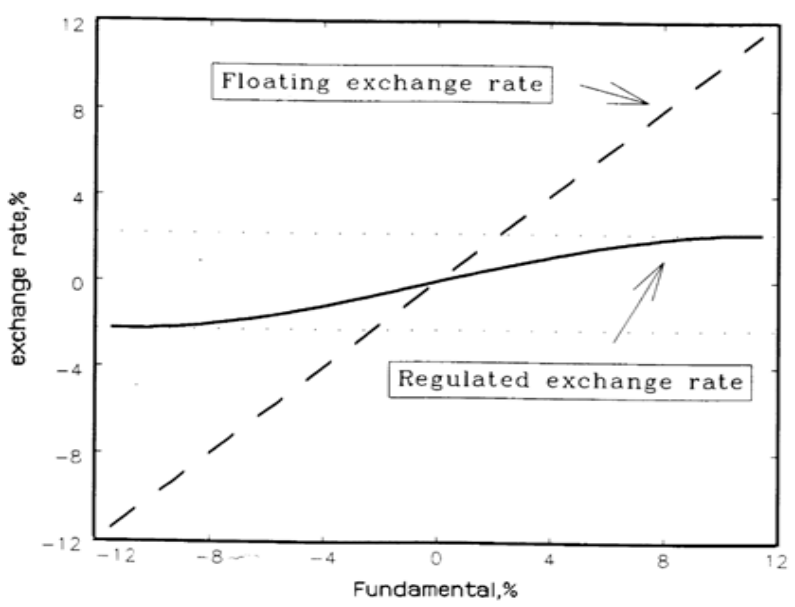

Fig. 1. Exchange rate function.

[3] Cleveland, W.S., S.J. Devlin and E. Grosse (1988), "Regression by Local Fitting", Journal of Econometrics, vol 37

[4] Diebold, F.X., and J.A. Nason (1990), "Nonparametric Exchange Rate Prediction?", Journal of International Economics, vol. 28

[5] Delgado, F., and B. Dumas (1991), "Target Zones, Broad and Narrow", in Krugman and Miller, eds., Exchange Rate Targets and Currency Bands, Cambridge University Press

[6] Duffie, D., and K.J. Singleton (1989), "Simulated Moments Estimation of Markov Models of Asset Prices", mimeo

[7] Flannery, B.P., W.H. Press, S.A. Teukolsky, and W.T. Vetterling (1986), Numerical Recipes, Cambridge University Press

[8] Flood, R.P., A.K. Rose, and D.J. Mathieson (1991), "An Empirical Exploration of Exchange Rate Target Zones", Carnegie-Rochester Series on Public Policy, 35

[9] Fuller, W.A. (1976), Introduction to Statistical Time Series, John Wiley \& Sons

[10] Gerard, C.F., and P.O. Wheatley (1989), Applied Numerical Analysis, Addison-Wesley

[11] Harrison, J.M. (1985), Brownian Motion and Stochastic Flow Systems, Robert E. Krieger Publishing Company 
[12] Ingram, B.F. and B-S. Lee (1991), "Simulation Estimation of Time-Series Models", Journal of Econometrics, 47

[13] Krugman, P.R. (1991), "Target Zones and Exchange Rate Dynamics", Quarterly Journal of Economics, 106

[14] Lindberg, H., L.E.O. Svensson, and P. Söderlind (1991), "Devaluation Expectations: The Swedish krona 1982-1991", IIES Seminar Paper no. 495

[15] Lindberg, H., and P. Söderlind (1991), "Testing the Basic Target Zone Model on Swedish Data", IIES Seminar Paper no. 488

[16] Lindberg, H., and P. Söderlind (1992), "Target Zone Models and the Intervention Policy: The Swedish Case", IIES Seminar Paper no. 496

[17] Newey, W.K., and K.D. West (1987), "A Simple, Positive Definite, Heteroskedasticity and Autocorrelation Consistent Covariance Matrix", Econometrica vol. 55, No. 3

[18] Perron, P. (1988), "Trends and Random Walk in Macroeconomic Time Series: Further Evidence from a New Approach", Journal of Economic Dynamics and Control, Vol 12

[19] Rose, A.K., and L.E.O.Svensson (1991), "Expected and Predicted Realignments: The FF/DM Exchange Rate during the EMS", IIES Seminar Paper no. 485

[20] Silverman, B.W. (1982), "Kernel Density Estimation using the Fast Fourier Transform", Applied Statistics, vol 31

[21] Smith, G.W., and M.G. Spencer (1991), "Estimation and Testing in Models of Exchange Rate Target Zones and Process Switching, in Krugman and Miller eds, Exchange Rate Targets and Currency Bands, Cambridge University Press

[22] Spanos, A. (1986), Statistical Foundations of Econometric Modelling, Cambridge University Press

[23] Svensson, L.E.O. (1991), "Target Zones and Interest Rate Variability", Journal of International Economics, 31

[24] Svensson, L.E.O. (1991), "The Simplest Test of Target Zone Credibility", Staff Studies, International Monetary Fund, 38

[25] Svensson, L.E.O. (1991), "The Term Structure of Interest Rate Differentials in a Target Zone: Theory and Swedish Data", Journal of Monetary Economics, 28 


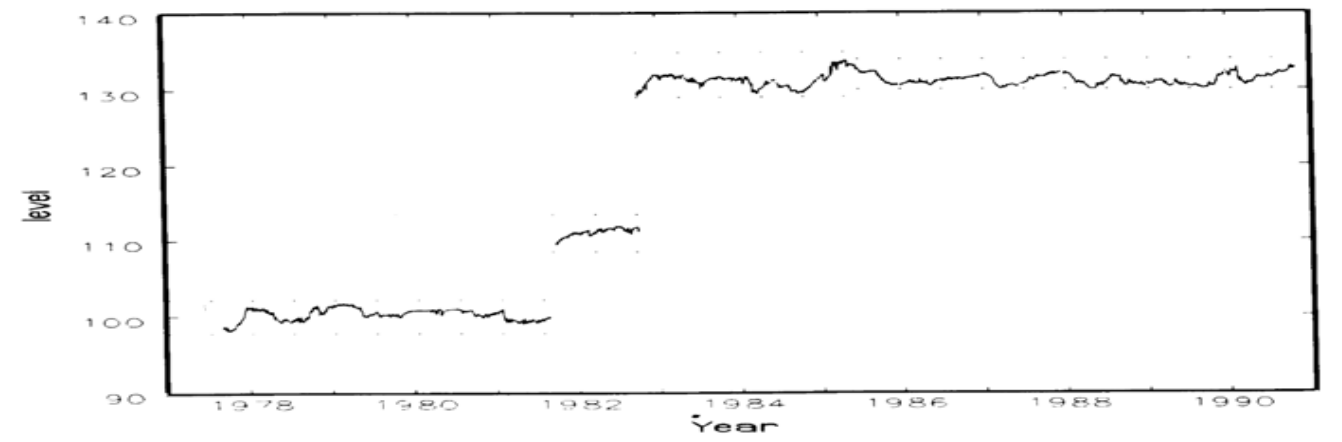

Fig. 2. Swedish currency index.

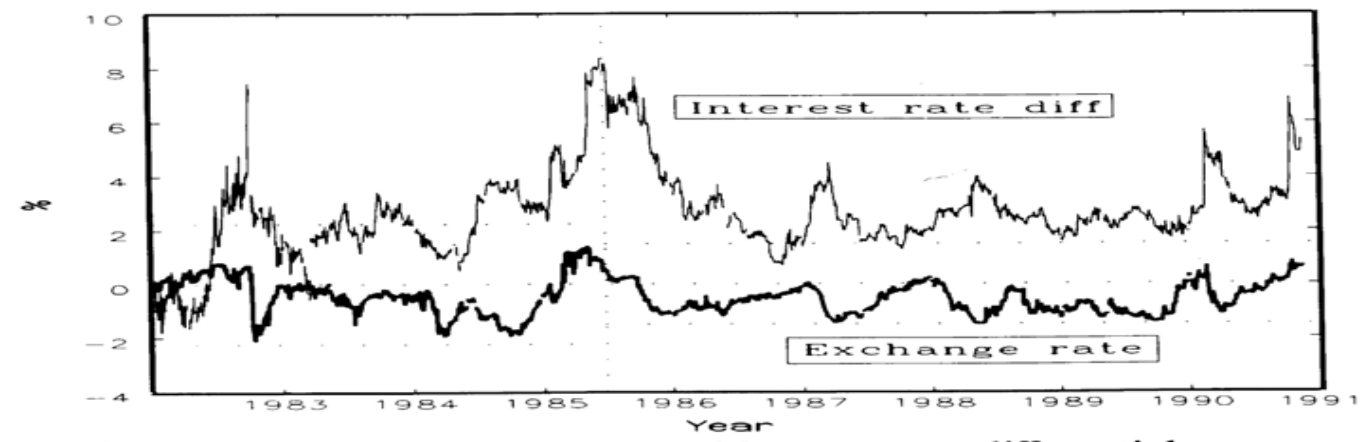

Fig. 3. Exchange rate and interest rate differential.

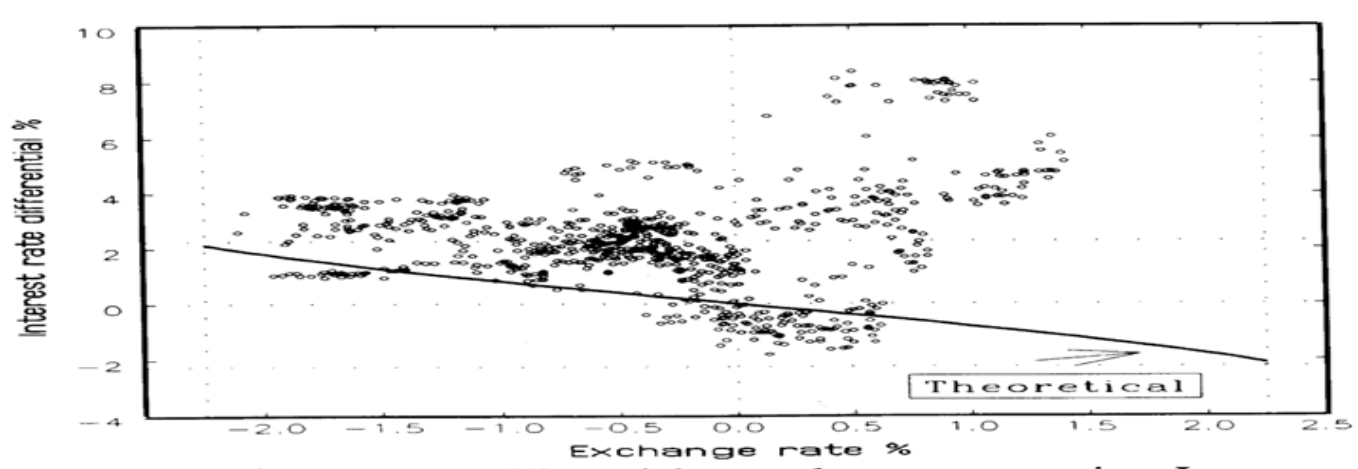

Fig. 4. Interest differential vs exchange rate, regime $I$. 


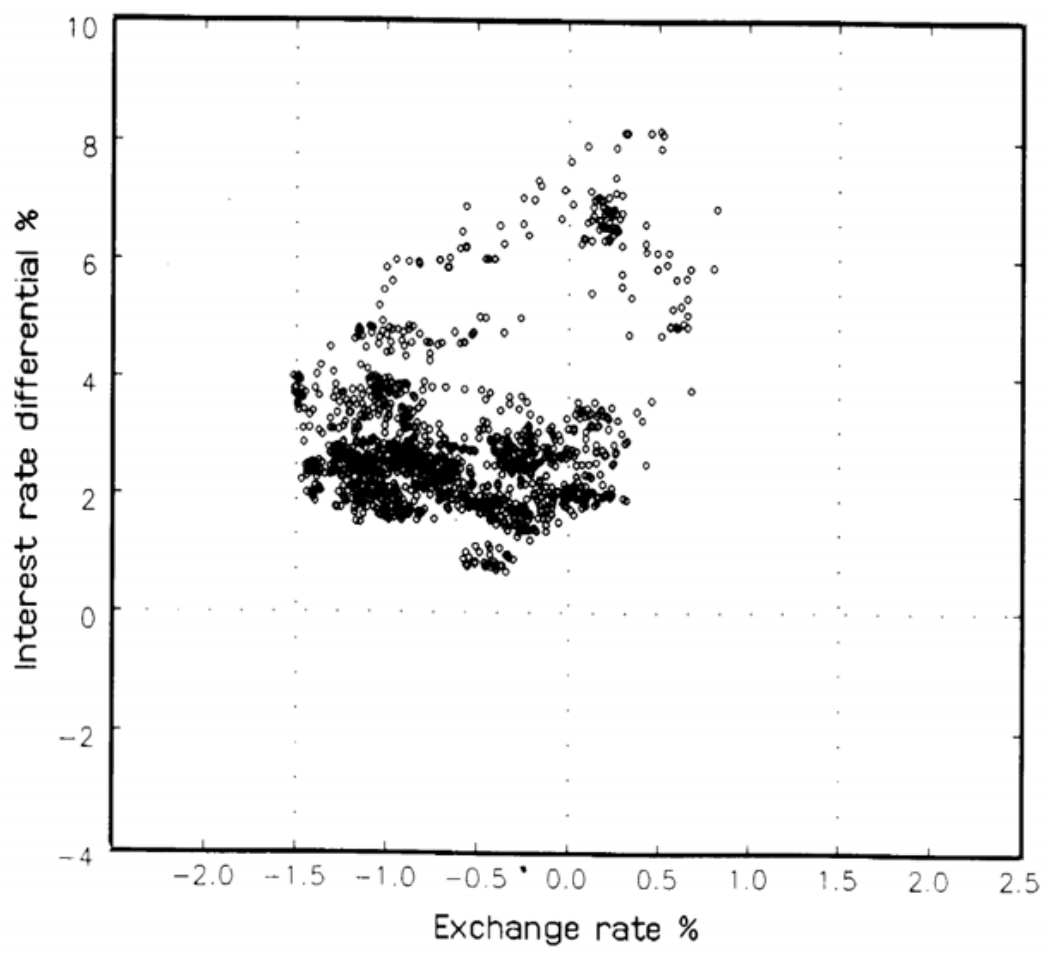

Fig. 5. Interest differential vs exchange rate, regime II. 


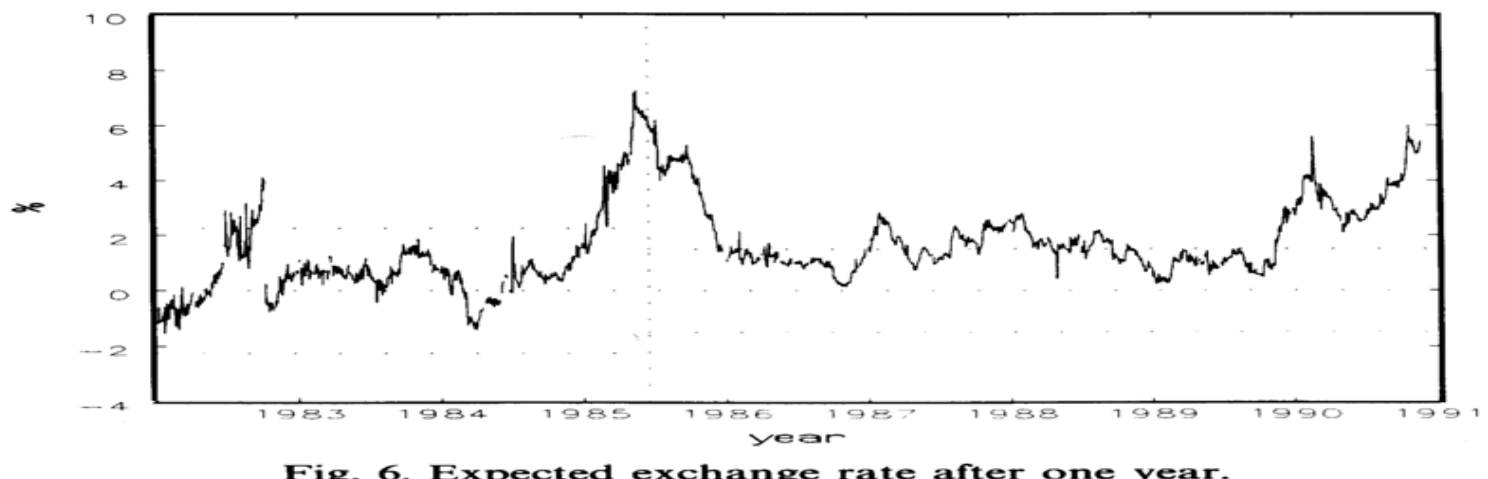

Fig. 6. Expected exchange rate after one year.
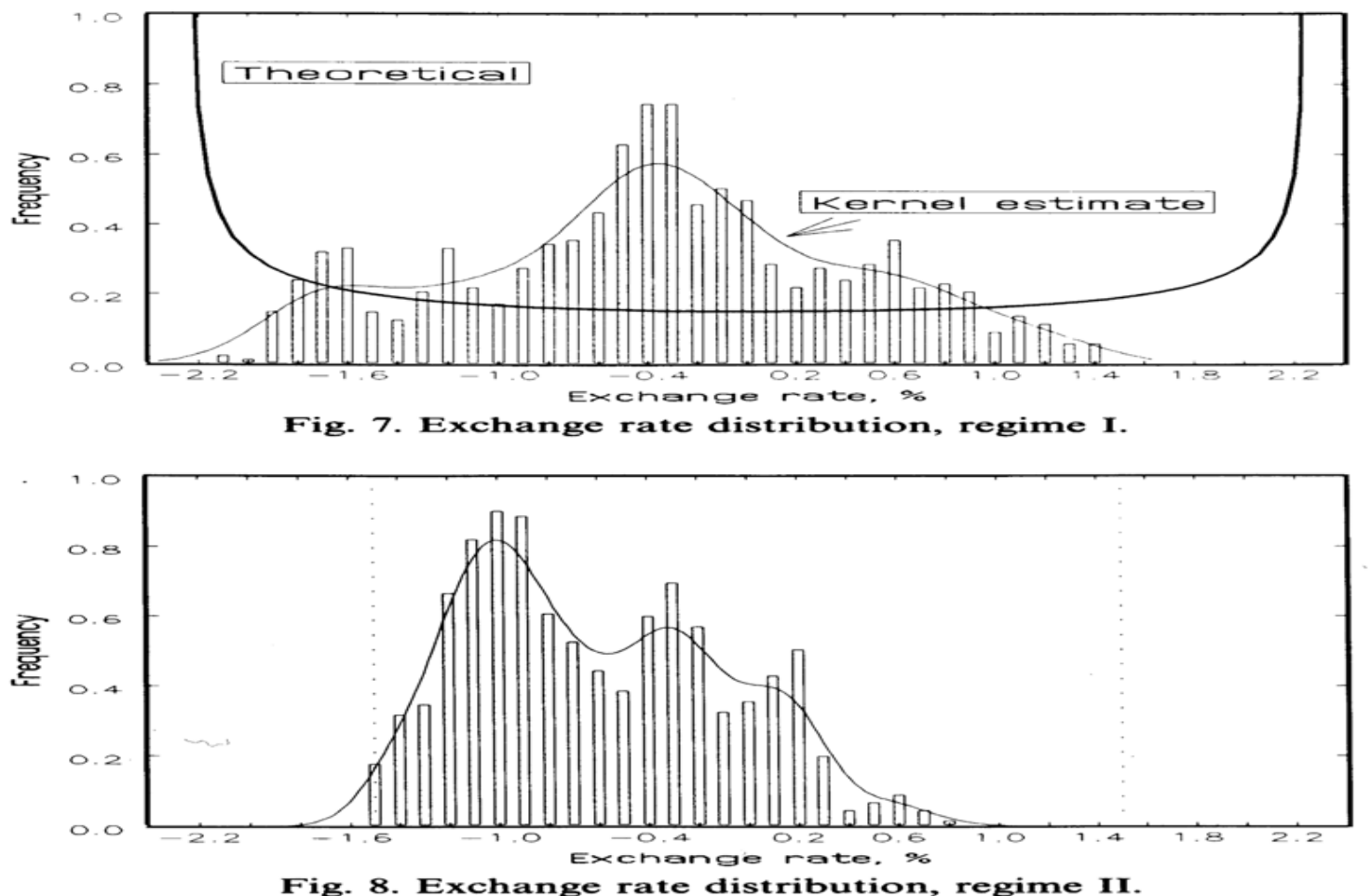


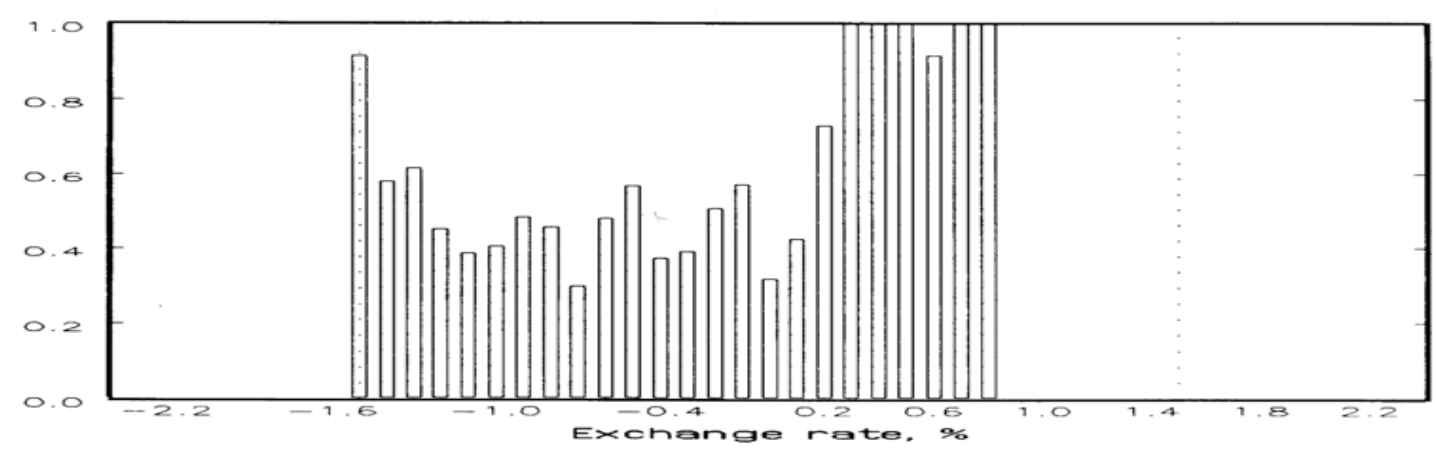

Fig. 9. Proportion of days with interventions.
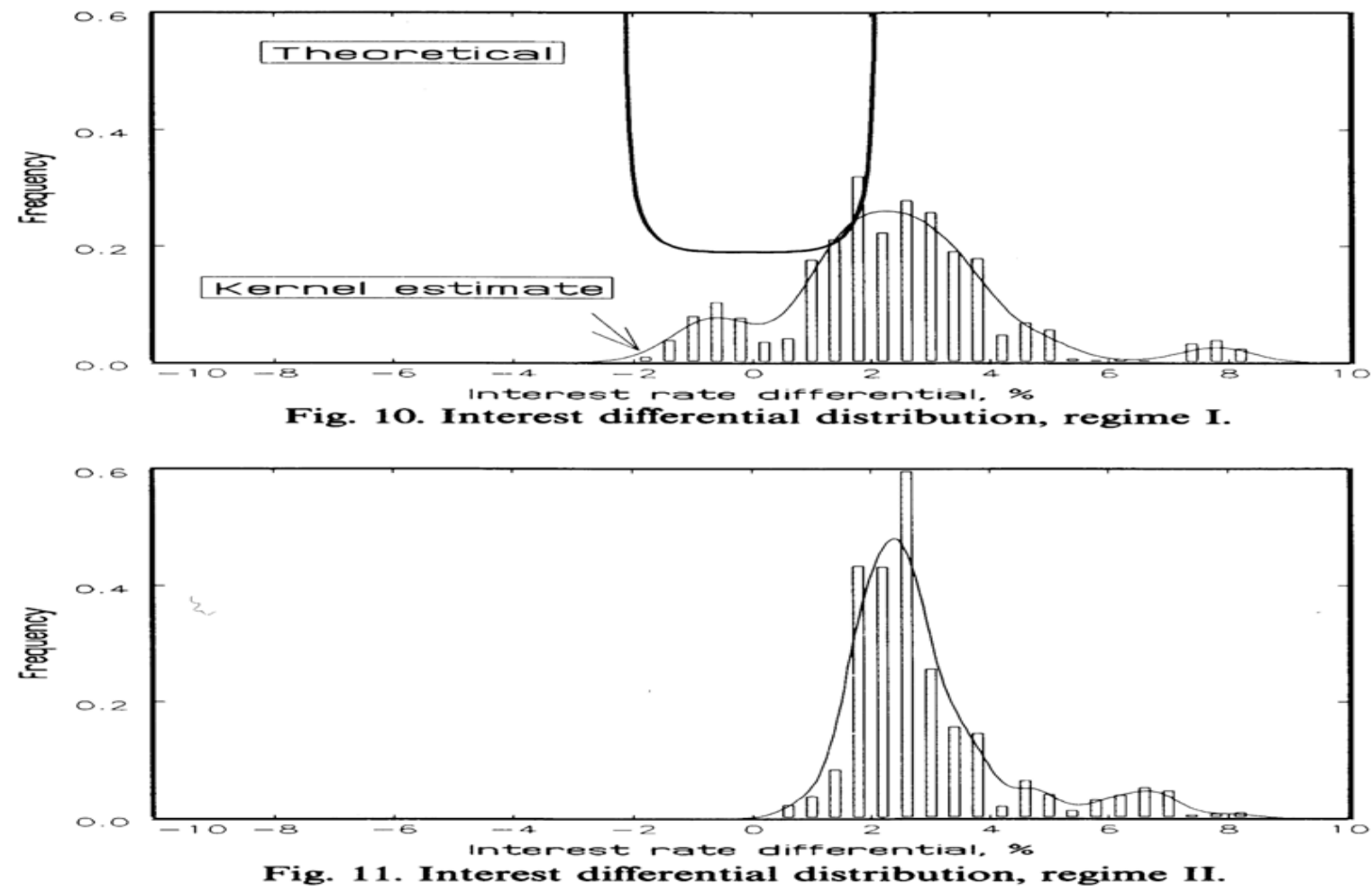


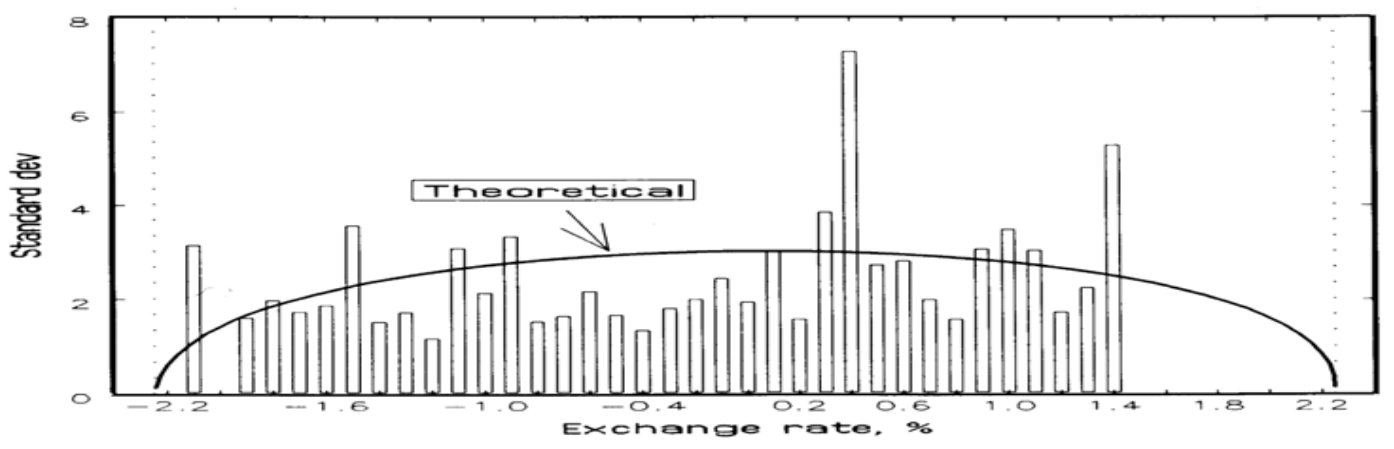

Fig. 12. Exchange rate conditional standard deviations, regime $I$.
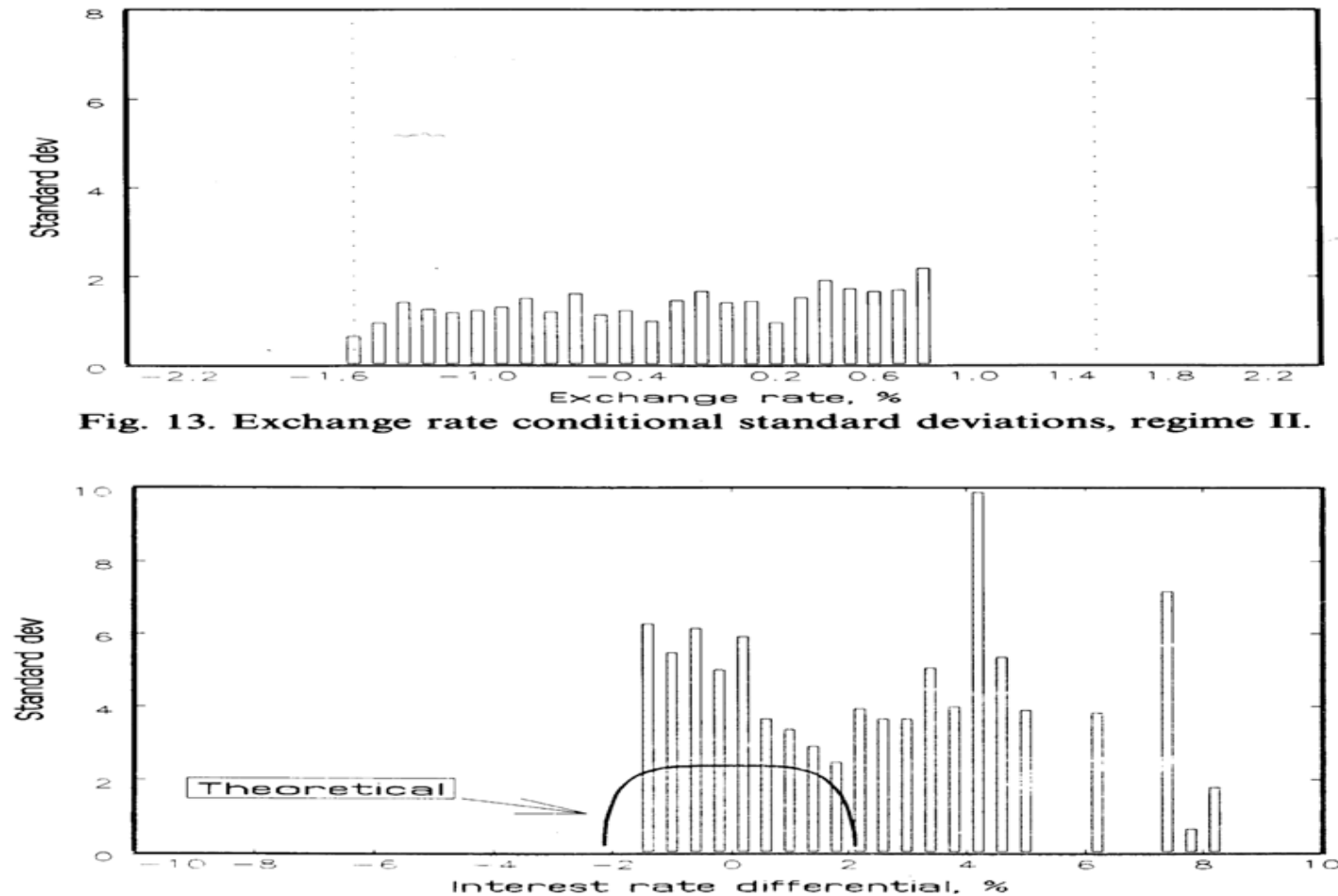

Fig. 14. Interest rate differential conditional standard deviations, regime $I$. 


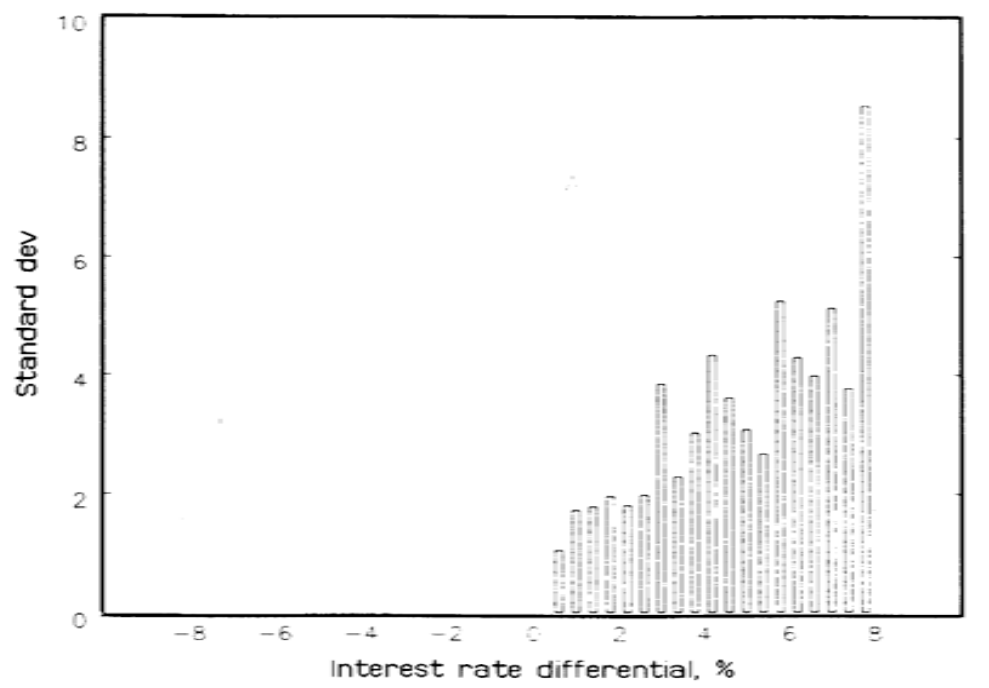

Fig. 15. Interest rate differential conditional standard deviations, regime II. 

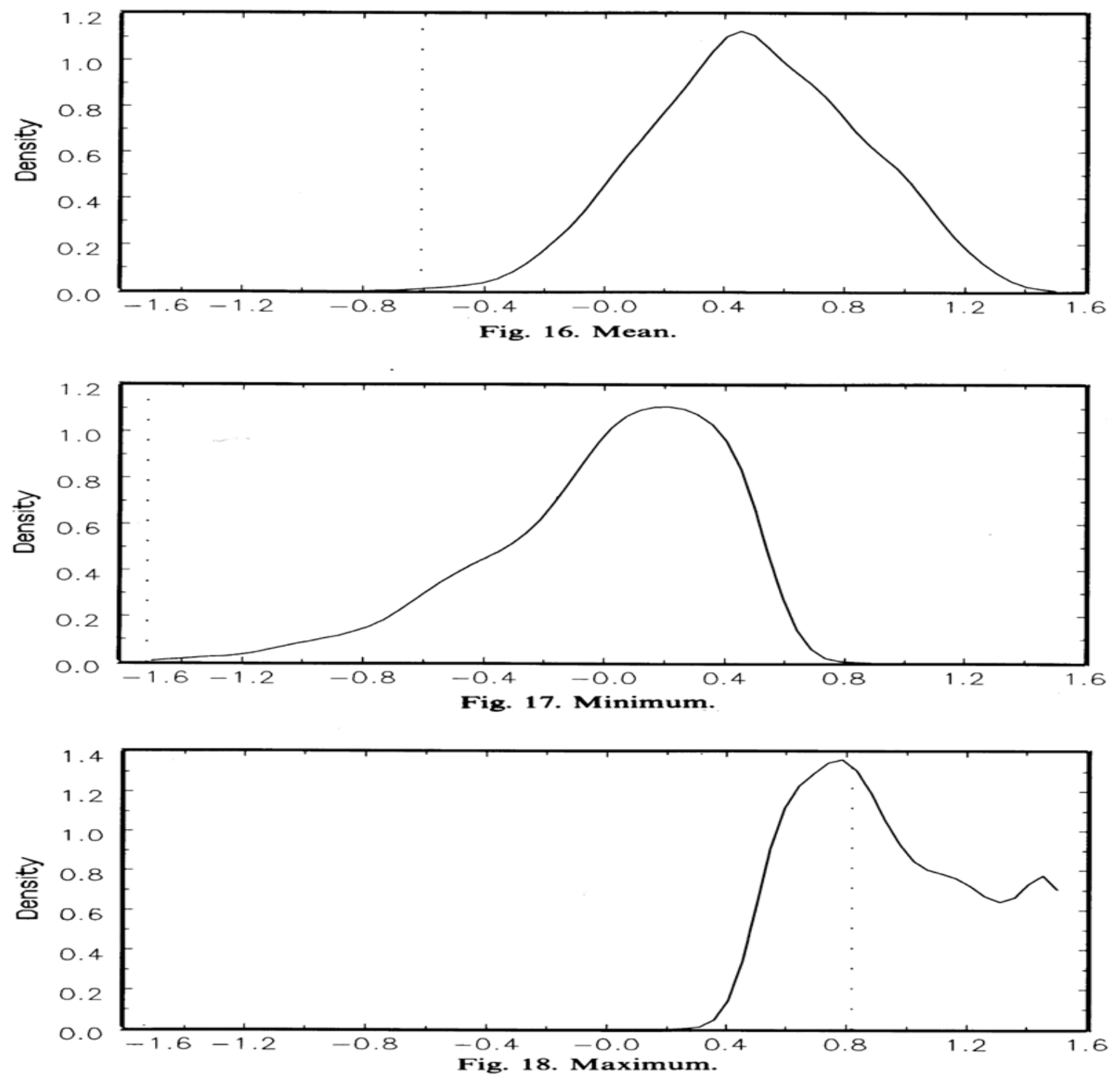

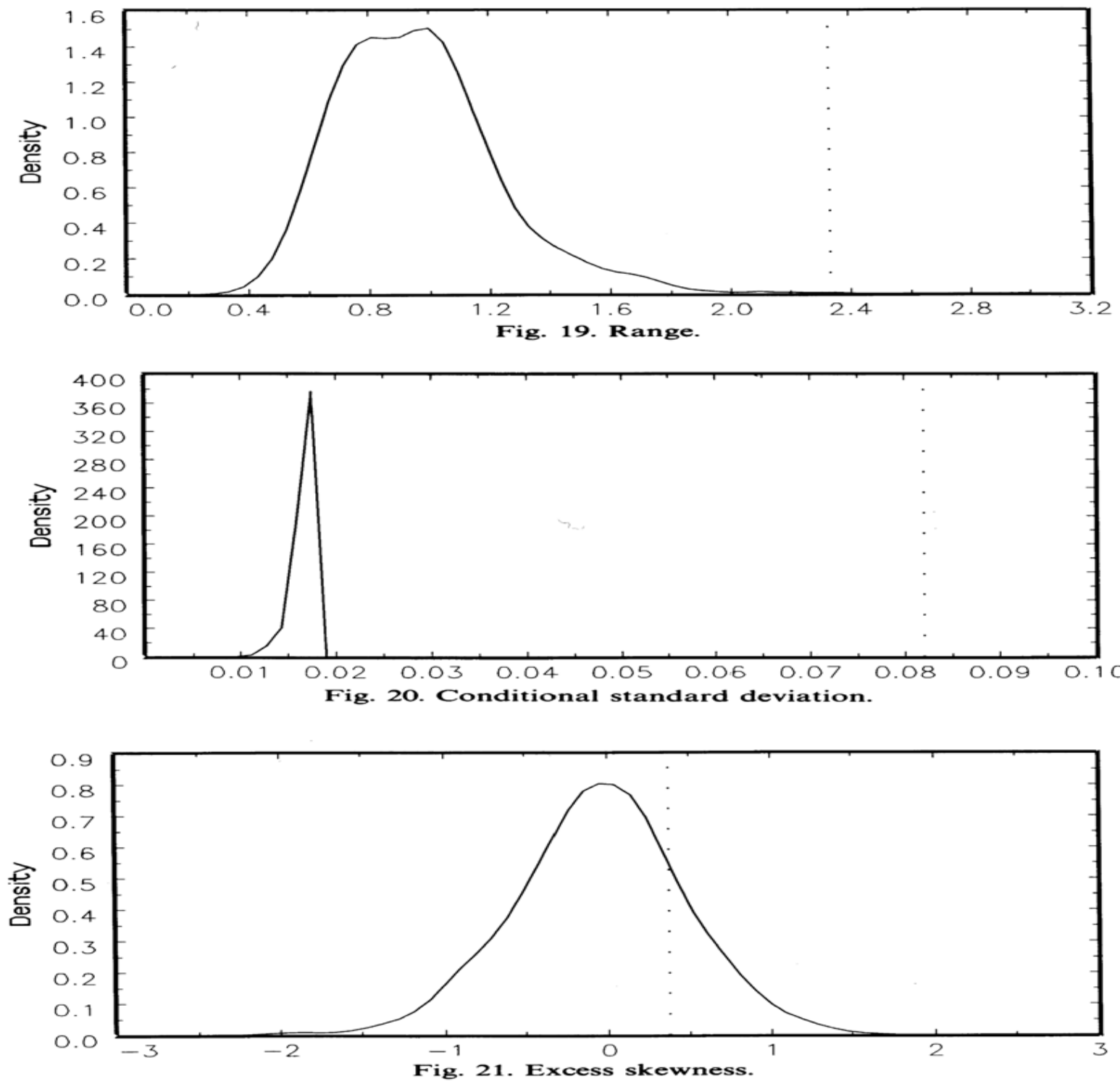

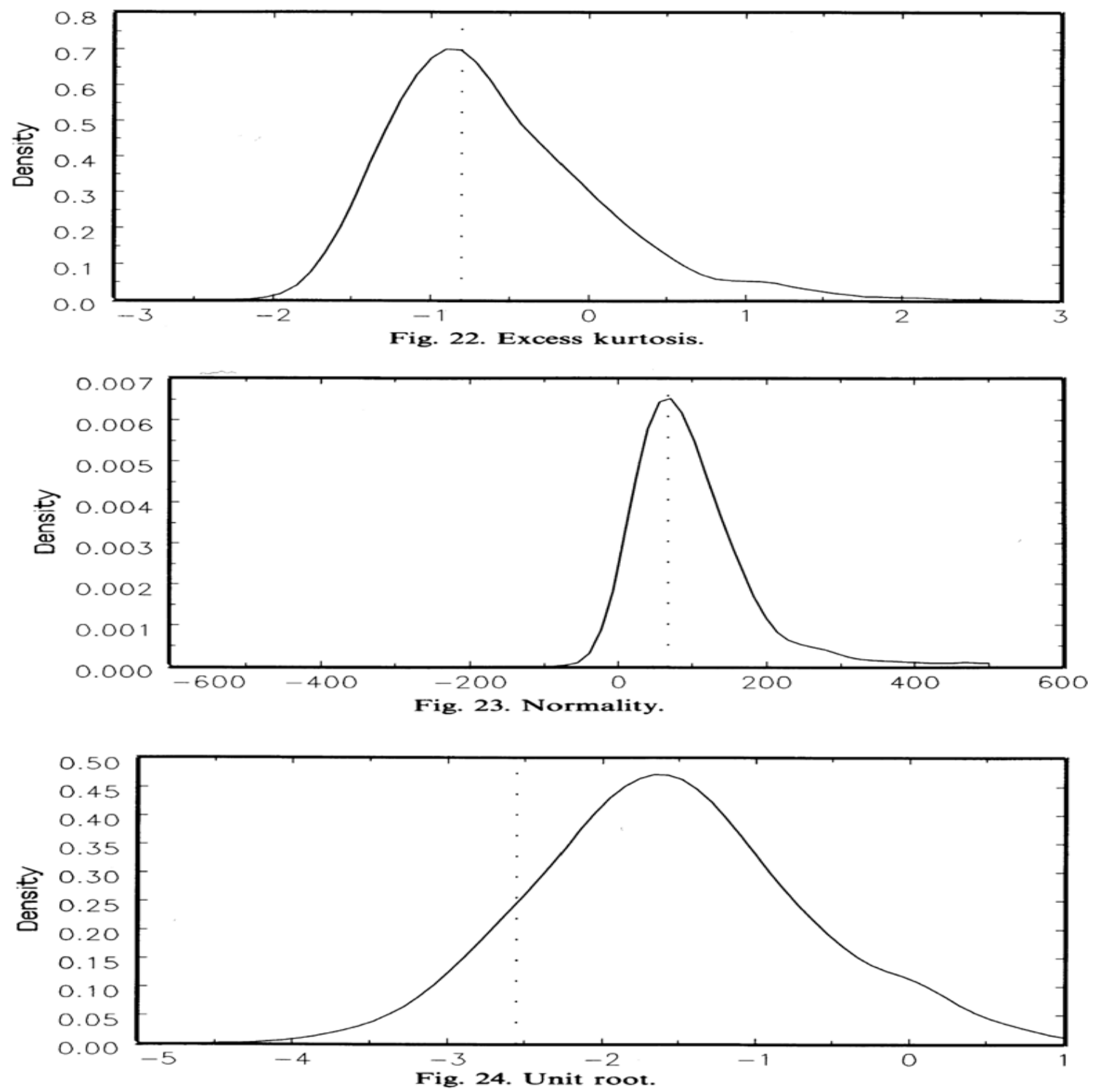